Trauma Surgery \& Acute Care Open

\title{
The history of Harborview Medical Center and the Washington State Trauma System
}

\author{
Eileen M Bulger, ${ }^{1}$ Janet Griffith Kastl, ${ }^{2}$ Ronald V Maier ${ }^{1}$
}

'Department of Surgery, University of Washington, Harborview Medical Center, Seattle, Washington, USA ${ }^{2}$ Washington State Department of Health, Office of EMS and Trauma, Olympia, Washington, USA

\section{Correspondence to}

Dr Eileen M Bulger; ebulger@u. washington.edu

Received 16 May 2017 Accepted 5 June 2017
To cite: Bulger EM, Kastl JG, Maier RV. Trauma Surg Acute Care Open 2017:2:1-7.

\section{ABSTRACT}

Harborview Medical Center serves as the sole adult and pediatric level I trauma center for Washington State, and its faculty have led efforts to develop comprehensive systems of trauma care across the country. The Washington State trauma system is an inclusive system that was developed based on data-driven decisions to distribute resources based on population need. This article seeks to explore the history of Harborview Medical Center and the development of the Washington State trauma system to identify the guiding principles and lessons learned, which can facilitate system development for a host of time-sensitive medical conditions.

\section{INTRODUCTION}

Harborview Medical Center in Seattle serves as the sole level 1 adult and pediatric trauma and burn center for the State of Washington (figure 1). In addition, Harborview serves as the safety net hospital for the community and is a mission-driven healthcare facility seeking to serve the most vulnerable residents of King County, while providing tertiary specialty care to the Pacific Northwest. The mission statement of the hospital speaks directly to the special groups of patients and programs that are given priority for care (box 1). In addition, Harborview serves as a leader in the community for disaster preparedness and is the Disaster Medical Control Center for the region.

The hospital is owned by King County, governed by the Harborview Board of Trustees and managed under contract by the University of Washington. All attending physicians are faculty of the University of Washington. Harborview also serves an important educational mission and is committed to support undergraduate, graduate, postgraduate and continuing educational programs for health professionals from the University of Washington as well as several other partner organizations. Harborview is the home for the regional paramedic training program, and Harborview faculty provide medical direction for the Seattle Medic One program and the Airlift Northwest flight programs, both of which were founded by Harborview clinicians.

As a result of its unique role in the community, Harborview is one of the busiest trauma centers in the country, with an average of 6000 trauma admissions per year, of whom 1000 are under the age of 18 and 700 are burn patients. Thirty-eight percent of trauma admissions have an Injury Severity Score $>15 \%$ and $50 \%$ of these are transfer patients. National benchmarking data suggest excellent risk-adjusted mortality for both the adult and pediatric trauma populations. Harborview faculty are also recognized as leaders in trauma and burn research and participate in multiple national clinical trials networks to advance the care of the injured patient.

The Washington State trauma system is an inclusive system, which was thoughtfully designed to distribute trauma centers based on population need and ensure access to trauma care even in the most rural areas of the state. This article seeks to explore the history of Harborview Medical Center and the development of the Washington State trauma system to identify the guiding principles and lessons learned, which can facilitate system development for a host of time-sensitive medical conditions.

\section{HISTORY OF HARBORVIEW MEDICAL CENTER}

The territory of Washington became an organized, incorporated territory of the USA in 1853 and its legislature first met in 1854. One of their first rulings was to make counties responsible for caring for all 'poor, sick, and homeless people whose relatives could not support them'. In 1877, King County opened a county 'poor farm' just south of Seattle to meet this need. Harborview Medical Center began as King County Hospital, which was a six-bed facility operating within the 'poor farm', and patients were cared for by nuns from the Sisters of Charity of the House of Providence. In 1894, a new 125-bed county hospital was commissioned for $\$ 80000$ and was located in Seattle's Georgetown neighborhood. A new wing was added in 1908 expanding to 225 beds. In 1928 there was a ballot measure to construct a 500-bed hospital for care of the 'indigent sick, injured, and maternity cases', and \$2.75 million was allocated to construct the new hospital on First Hill in Seattle, which is the site of the facility today. The Seattle Times held a contest to name the new hospital and the award went to the name 'Harborview' due to the location on a hill overlooking Puget Sound and the Seattle waterfront. ${ }^{1}$

Harborview was home to one of the first nursing schools in the region opened by the University of Washington in 1931. Nursing students lived on campus in a building across the street from the hospital. In the mid-1940s, Harborview was the primary facility for treatment of patients suffering from the polio epidemic, and the first blood bank in King County was established at Harborview. In 1946, the University of Washington School of Medicine was established and the first chair of surgery, Dr Henry N Harkins, was based at Harborview until construction of the new University Hospital was completed in 1959. In 1956, the first open 


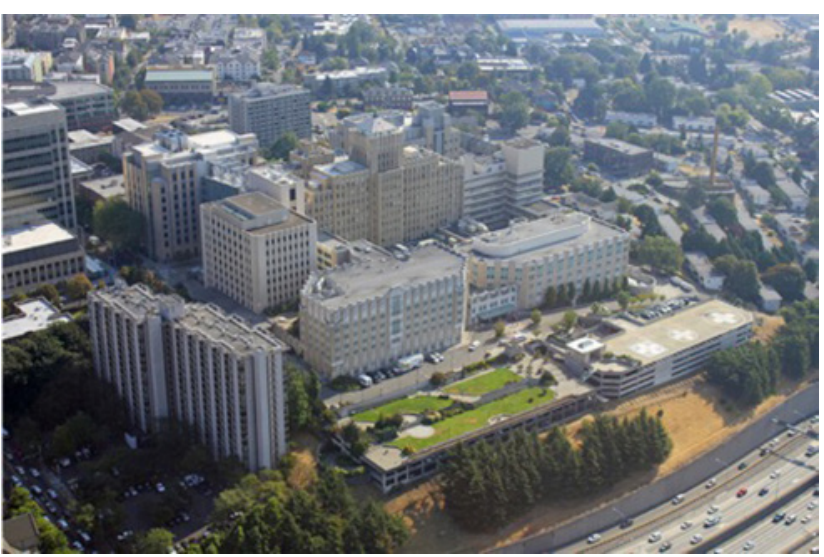

Figure 1 Aerial photo of the current Harborview Medical Center campus, Seattle, Washington.

heart surgery on the West coast was performed at Harborview by Alvin K Merendino, MD. ${ }^{1}$

In 1967, the University of Washington entered a formal agreement with King County to take over clinical management of Harborview, and all physicians were recognized as academic faculty of the University of Washington. In 1969, the Seattle Medic One program was founded by Dr Leonard Cobb, a Harborview cardiologist, and Seattle Fire Chief Gordon F Vickery. As detailed below, this pilot program became one of the most successful paramedic training programs in the country, and although the initial focus was on resuscitation from cardiac events, advances in prehospital care for the injured soon followed. As a result, Harborview became known as the regional referral center for emergency care especially for the seriously injured patient.

In 1973, Dr G Tom Shires was recruited as the chair of surgery at the University of Washington, and Drs James Carrico and Peter Canizaro became the co-chiefs of surgery at Harborview. Their interest in trauma care led to the development of Harborview as the premier trauma center for the region for both adults and children. In 1974, Dr P William Curreri became the director of the new regional burn center at Harborview. Harborview continued to expand its facilities with expanded operating room (OR), emergency room (ER), intensive care unit (ICU), and clinic space opening in both 1997 and 2008, with a current licensed bed capacity of 413 beds, of which 98 are critical care beds. In 1994, Ronald V Maier, MD, became the Chief of Surgery, a role he continues to hold to this day. Under Dr Maier's leadership, the Division of Trauma and Burn Surgery has grown to 12 full-time

\section{Box 1 Harborview Medical Center mission populations}

- Persons who are non-English-speaking poor

- Persons who are uninsured or underinsured

- Persons who experience domestic violence

- Persons who experience sexual assault

- Persons incarcerated in King County jails

- Persons with mental illness, particularly those treated involuntarily

- Persons with substance abuse

- Persons with sexually transmitted diseases

- Persons who require specialized emergency care

- Persons who require trauma care

- Persons who require burn care general surgery faculty with an average of $\$ 2$ million per year in research funding. The general surgery service has always functioned as an acute care surgery (ACS) service covering all general surgical emergencies as well as running an elective practice in addition to trauma care. This model is important to maintain surgical skills as blunt trauma has become increasingly nonoperative for general surgeons. All ACS faculty are also board-certified in surgical critical care and attend in the trauma/surgical ICU. Harborview Medical Center also had a cadre of dedicated subspecialty surgical faculty, including thoracic surgery, vascular surgery, plastic surgery, neurosurgery, orthopedics, urology, gynecology, otolaryngology, oral maxillofacial surgery, and integrated services for spine and hand surgery. These services have multiple fellowships for advanced trauma care and contribute to the robust research environment.

Another advantage of the development of the University of Washington Department of Surgery at both Harborview and the University Hospital is that it has allowed separation of the major surgical programs between the two hospitals. Trauma and burn care are provided solely at Harborview, whereas transplantation and elective cardiac surgery are provided solely at the University Hospital. Many other University of Washington surgical specialties have followed this approach. The result is that the OR and ICU capacity at Harborview can focus extra time and resources on all aspects of trauma and emergency surgical care. The regionalization of care established by the trauma system has been extended to a wide variety of surgical emergencies, such as necrotizing soft tissue infections, ruptured abdominal aortic aneurysms, spontaneous intracranial hemorrhage, etc. In the current climate of increasing competition and the economic pressures facing safety net hospitals, the broad clinical spectrum of emergent and elective surgical care ensures the resilience and sustainability of the institution.

\section{HISTORY OF SEATTLE MEDIC ONE AND DEVELOPMENT OF EMERGENCY MEDICAL SERVICES (EMS)}

In the late 1960s Harborview physicians recognized the need for more rapid intervention for patients suffering from cardiac events. Dr Leonard Cobb, a cardiologist, approached Seattle Fire Chief Gordon F Vickery about a pilot program to improve the medical training for Seattle firefighters and organize an approach to medical emergencies. In 1969 the first class of 15 Seattle department firefighters began a training program focused on the care of patients with cardiac events. This program included 200 hours of classroom instruction and 700 hours of clinical training in the Harborview Medical Center ORs and emergency department. This training included 12 lead electrocardiagram interpretation, intravenous access, endotracheal intubation, defibrillator use, and pharmacologic therapy. Service to the public began in March of 1970 with a large mobile home known as 'Moby Pig', which was jointly staffed by physicians and the newly trained paramedics. ${ }^{2}$ This program was quickly recognized for its success in saving lives after acute coronary events, and training was expanded to cover all acute medical emergencies and traumatic events. In 1972, Washington State amended the Medical Practice Act to establish the profession of EMS and eliminate the need for direct on-scene physician supervision. This legislation defined minimum standards for basic, intermediate, and advanced life support training, and led to the formal establishment of the EMS Standards Committee of the Washington State Medical Association (WSMA). An EMS office was also established at the Department of Health (DOH). 
In 1975 the Medic One program expanded to include training of paramedics from all agencies in King County with recognized certification as Mobile Intensive Care Paramedics by the Washington State DOH. Dr Michael Copass, Medical Director of Harborview emergency services, served as the medical program director and director of Medic One paramedic training for over 30 years. Dr Copass is known for his exacting standards for highquality patient care and professionalism. This training program is now one of the most comprehensive programs in the country and is highly competitive. Eligible candidates must have at least 3 years of firefighter/Emergency Medical Technician (EMT) experience and are sponsored by their EMS agency. Medic One paramedic students receive 2000 hours of instruction, which includes classroom work, clinical training in the Harborview ER and OR, and supervised field training by senior paramedics. The result is over 700 patient contact hours, which is three times the national standards.

The system was designed as a tiered response with trained dispatcher triage. Immediate response to critical events involves the local fire service with all firefighters trained at the basic EMT level and prepared to intervene with immediate initiation of cardiopulmonary resuscitation (CPR) and defibrillation when indicated. The average response time is 3 to 4 minutes followed by paramedic unit, staffed with two paramedics to provide additional advanced life support care. A public campaign known as Medic Two was also initiated to focus on citizen CPR training, which has resulted in over 50\% of King County residents completing this certification. The results of this program have consistently demonstrated the highest cardiac arrest resuscitation rates in the USA. In 1974, Morley Safer reported a story on 60 minutes where he was quoted as saying "If you are going to have a heart attack, have it in Seattle."

From the beginning, the Medic One program has been focused on ongoing quality improvement efforts and research to improve prehospital care. Many of the seminal studies developing out of hospital resuscitation for cardiac arrest were conducted by Harborview investigators in collaboration with Medic One. While much of the country was wrestling with the scope of practice of EMS providers, Seattle Medic One research documented a $98.4 \%$ success rate with prehospital intubation including the use of neuromuscular blockade. ${ }^{3}$ Continuing education and skills training are provided in the Harborview ORs. From 2004 to 2017 the Medic One programs throughout King County were actively involved in the Resuscitation Outcomes Consortium, an National Institutes of Health (NIH)-funded clinical trials network to advance prehospital research in cardiac arrest and life-threatening trauma. The Medic One Foundation also issues annual grant awards to local investigators to conduct studies to improve prehospital care. The early success of the Medic One programs and the tight integration with Harborview Medical Center physicians were instrumental in the subsequent development of the statewide trauma system and laid the foundation for Harborview as the primary referral center for major trauma in the region.

Dr Michael Copass is also credited with establishing Airlift Northwest (ALNW), the first regional aeromedical service in Seattle. Inspired by the death of four children in a house fire in Sitka, Alaska, in 1982, Dr Copass identified the need for a regional aeromedical transport service to support the timely transport of patients from southeast Alaska for advanced care. Airlift Northwest was founded in 1982 and currently has seven helicopter and fixed wing bases in Western Washington, and fixed wing and turboprop services based in Juneau, Alaska, and Yakima, Washington. ALNW transports an average of 1500 patients per year to Harborview Medical Center.

\section{DEVELOPMENT OF THE WASHINGTON STATE TRAUMA SYSTEM}

In the 1980s, the EMS Standards Committee of the WSMA, chaired by Lothar Pinkers, MD, a surgeon from Bellevue, Washington, and made up of EMS directors from across the state, began discussing the pros and cons of organized trauma care, including the selection of certain hospitals to care for the most seriously injured. A number of states and counties across the nation had established designated trauma care centers, and a growing body of data showed the value of such organizations, at least in urban settings. At the same time, there were two counties in Washington State (Pierce and Walla Walla) that attempted to organize and designate hospital-based trauma care on the county

Table 1 Guiding principles and recommendations for Washington State trauma system implementation

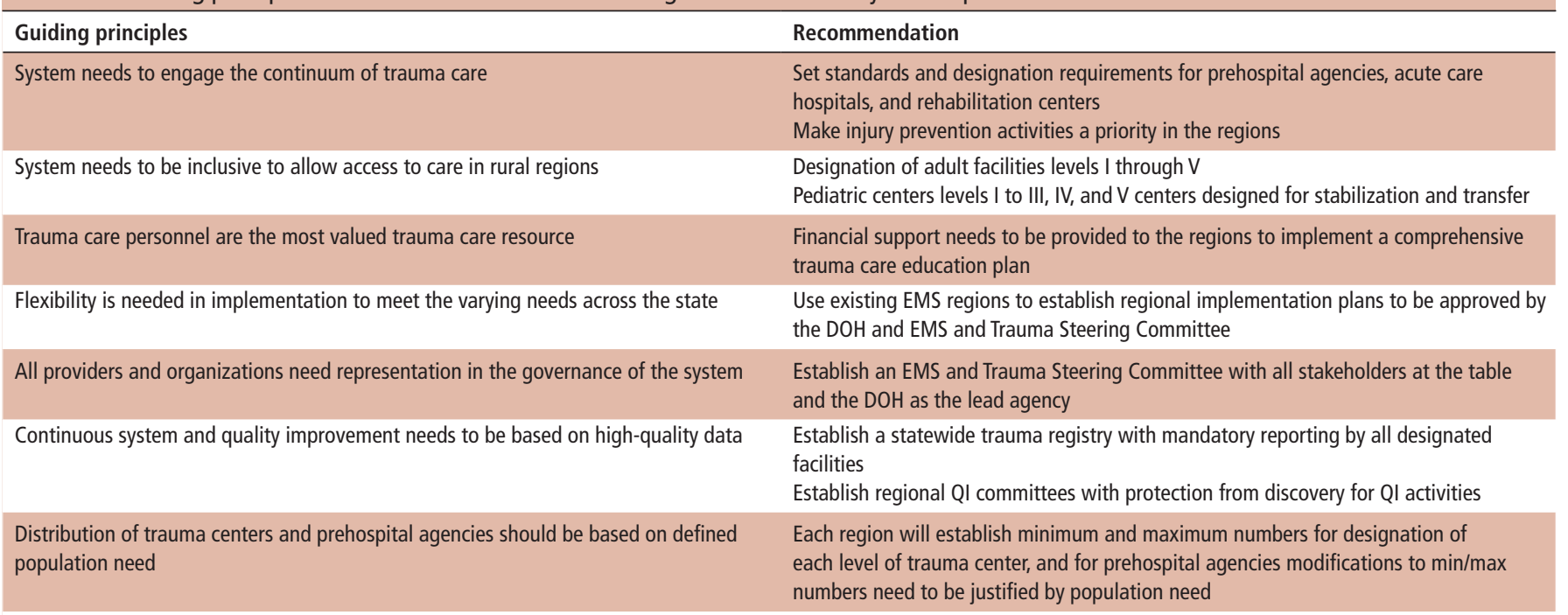

The system needs dedicated trauma system funding to maintain operations and address Create and allocate a source of funding for a dedicated trauma system fund gaps in reimbursement of undercompensated care

DOH, Department of Health; EMS, emergency medical service, QI, quality improvement. 


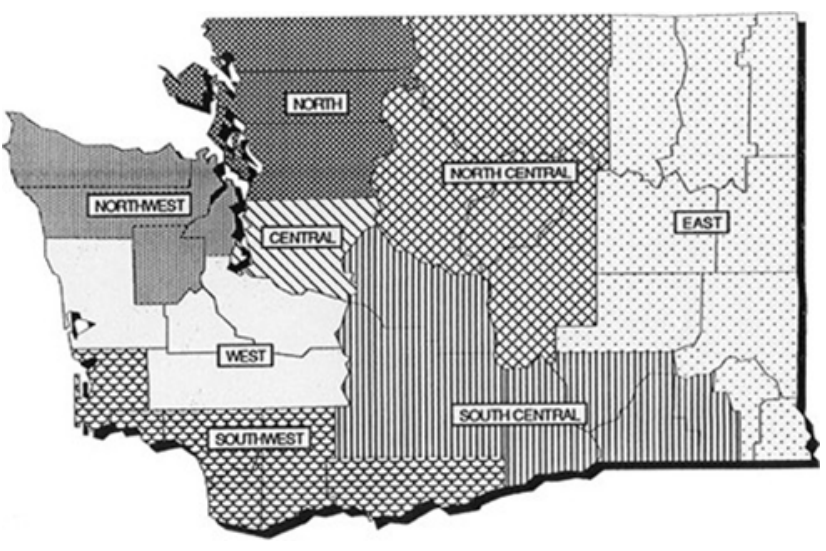

Figure 2 Eight emergency medical service regions in Washington State that were used to establish the regional council structure for the state trauma system.

level. In Walla Walla this effort was challenged legally, and it was determined that for a county to select designated trauma services would be violation of Anti-Trust laws, but that the state did have the authority to make such designations.

As a consequence of these events and with the advice of the EMS Standards Committee of the WSMA, the state office of EMS convened an Ad Hoc Workgroup including leaders of the EMS and the broader healthcare community to study the question of whether Washington State needed an organized trauma care system extending into the hospital setting. This workgroup included representatives of WSMA, the Washington State Hospital Association, American College of Surgeons, American College of Emergency Physicians, Fire Chiefs Association, Council of Fire Fighters, Washington State Ambulance Association, Emergency Nurses Association, law enforcement agencies, and others involved in the care of seriously injured people in the state. The committee was chaired by Dr Marvin Wayne. The state also hired a consultant to conduct a review of other state/county trauma care systems and perform a data analysis of the need for trauma care in Washington State. This was completed in late 1987. At the same time, a leader on healthcare issues in the Washington State legislature, Representative Dennis Braddock, decided to introduce a bill that would call for the planning and establishment of a trauma care system for Washington State. The information collected by and the recommendations of the Ad Hoc Workgroup were used to formulate this bill as a formal study and planning effort to define the need for and a proposed implementation model for a statewide system.

This bill was passed into law as the Trauma Care Study Act of 1988 and called for the appointment by the Governor of a formal Trauma Care Steering Committee, chaired by Dr Jim Nania from Spokane, Washington. The committee was given the task of conducting a study of trauma care in Washington, developing a comprehensive trauma system plan and reporting recommendations to the Governor and legislature in January 1990, along with proposed implementation legislation. ${ }^{45}$ The Steering Committee again included representatives of all the key EMS and trauma care provider groups in the state, statewide geographic representation and public representation. In addition to the committee, over 100 other interested experts within the state volunteered to participate in one of five technical advisory committees: data, prehospital, hospital, pediatric, and cost and public policy. The bill established a Trauma Trust Account funded for 2 years from the Public Safety and Education Account. This

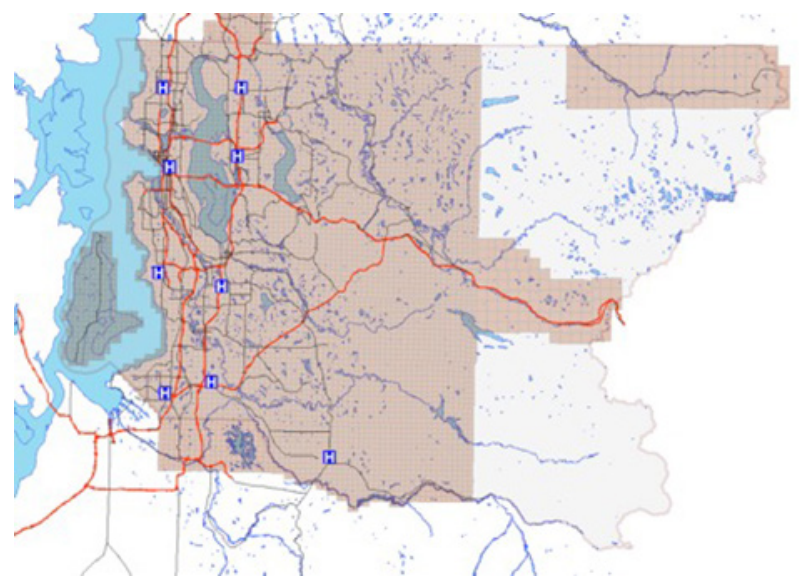

Figure 3 Geographic distribution of trauma centers in King County, Washington (central region).

2-year project provided the opportunity to assess current level of trauma care in the state, identify needs, and develop solutions to improve outcomes of seriously injured patients in Washington. It also provided a forum to consider and address concerns by the provider community through an inclusive process of system development. Surveys of resources and opinions of all levels of EMS and trauma care were conducted. In addition, a prospective patient tracking study was conducted. This study was unique in that it set up prospective data collection for injured patients starting at the time of injury and extending through rehabilitation. Participation was voluntary, but approximately $85 \%$ of hospitals with an ED and nearly all licensed ambulance companies in the state agreed to participate. All patients meeting the prehospital trauma center triage criteria as described by the American College of Surgeons who were subsequently admitted to a hospital were included. Information on over 4000 patients was collected in 1 year. These data provided valuable information to identify the distribution of injured patients in the state and the current access to care and outcomes. These data identified significant disparities across the state in trauma care and outcomes especially in rural areas. Costs of system development and implementation were also reviewed. A five-volume report was generated for the Washington State legislature by the committee. This report designed a comprehensive EMS and trauma care system model and provided extensive specific recommendations regarding its implementation. ${ }^{6}$ The guiding principles defined by this committee and recommendations for system design are listed in table 1.

The 1990 Trauma Care Systems Act, which was passed unanimously, set into law these recommendations and established a permanent Governor's EMS and Trauma Steering Committee, which was initially chaired by Dr Nania. The system was integrated into the existing EMS System, which included regulation of EMS services and personnel, EMS training, and systems development through eight regional EMS councils (figure 2). It called for a comprehensive integrated systems approach to trauma care following the continuum of care. The system components include injury prevention, prehospital EMS and trauma care, hospital trauma care, and trauma rehabilitation. It established the Washington State DOH as the lead agency, authorized to verify prehospital trauma care services, establish trauma triage criteria, designate five levels of adult and three levels of pediatric trauma care services, and for the first time in the nation to designate trauma rehabilitation services. The eight EMS regional councils were expanded to require representation of hospital 


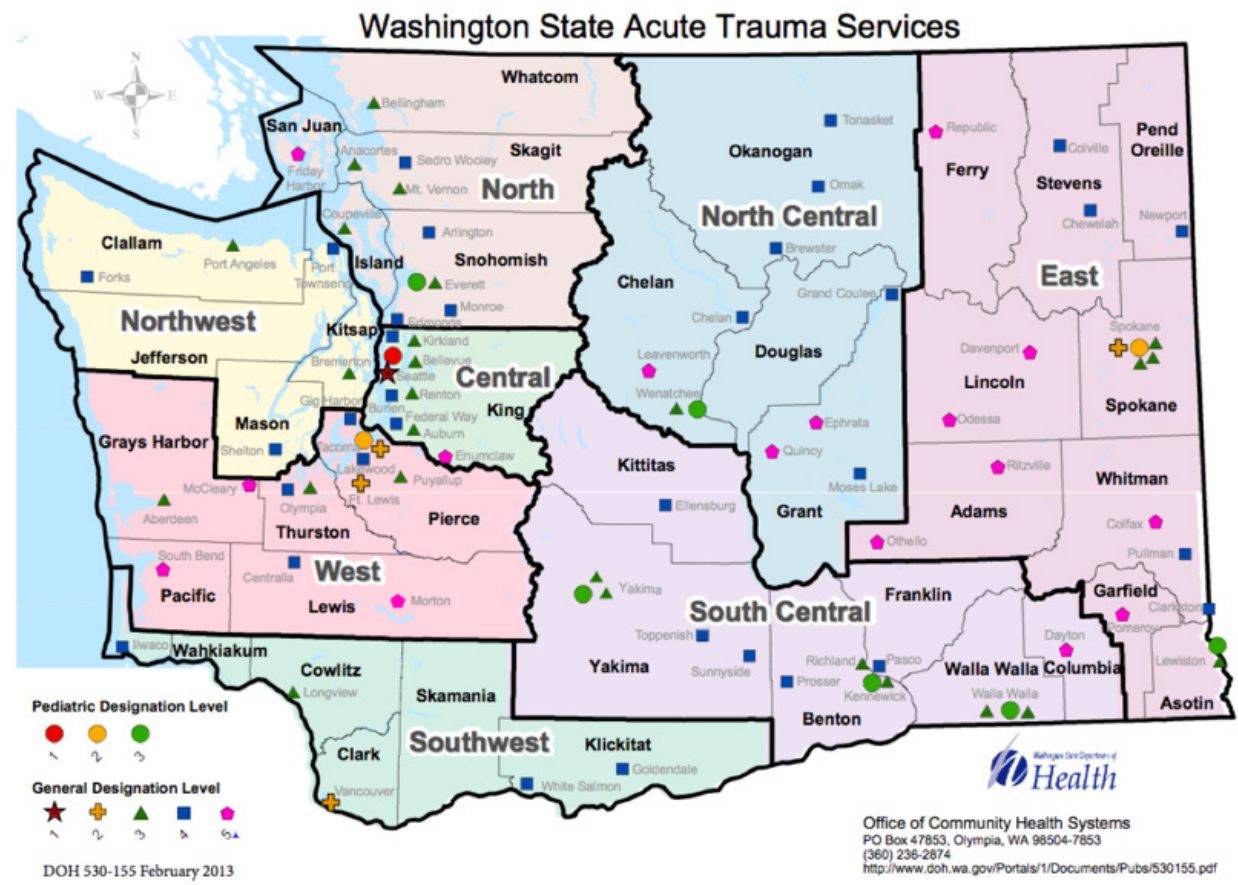

Figure 4 Current map of designated trauma centers in Washington State.

Table 2 Representation on the Washington Emergency Medical services (EMS) and Trauma Steering Committee

\begin{tabular}{ll}
\hline Organizations & $\begin{array}{l}\text { Number of } \\
\text { representatives }\end{array}$ \\
\hline American College of Surgeons Committee on Trauma & 3 \\
\hline American College of Emergency Physicians & 3 \\
\hline $\begin{array}{l}\text { Washington State Hospital Association (urban and rural } \\
\text { representatives) }\end{array}$ & 2 \\
\hline WA Chapter of American Academy of Pediatrics & 1 \\
\hline EMS Medical Program Directors & 1 \\
\hline Neurosurgery society & 1 \\
\hline Orthopedic society & 1 \\
\hline Neurology society & 1 \\
\hline Emergency cardiac and stroke system (one physician, one & 2 \\
nurse) & 1 \\
\hline WA State Emergency Nurses Association & 1 \\
\hline WA State Nurses Association & 1 \\
\hline WA State Trauma Nurse Network & 1 \\
\hline Washington Fire Chiefs Association & 2 \\
\hline WA State Council of Fire Fighters & 1 \\
\hline WA State Fire Commissioner & 1 \\
\hline WA State Fire Fighter's Association & 1 \\
\hline General EMS representative & 1 \\
\hline Association of Rehabilitation Facilities & 1 \\
\hline WA State Poison Control Center & 1 \\
\hline Law Enforcement - Washington State Patrol & 1 \\
\hline Washington Ambulance Association & 1 \\
\hline Association of Washington Cities & 1 \\
\hline Air Medical Services & 1 \\
\hline General public member & 1 \\
\hline
\end{tabular}

providers, public health, law enforcement, and the public, as well as prehospital care providers. The regional councils were tasked with creating the specific plans for level and distribution of prehospital and hospital trauma services, implementation of training and prevention programs, and establishing patient care procedures identifying the who, what, and where of system implementation according to the triage criteria. Healthcare personnel were identified as the most abundant and valued trauma care resource in the state, and so $40 \%$ of budgetary expenses were designated to provide trauma education in the regions. This included mobile training groups to reach the rural facilities and funds to offset the costs for physicians to attend the Advanced Trauma Life Support programs. Grants funds were identified for the regions to complete their new duties and provide continued support for EMS development in the communities. The law established a trauma care registry in the $\mathrm{DOH}$ and created regional quality improvement committees, with broad confidentiality protections, within each of the eight EMS and trauma care regions.

In 1990, the work of implementing this comprehensive system became the challenge of the $\mathrm{DOH}$, the expanded Governor's EMS and Trauma Care Steering Committee, and the regional councils. The regions were required to identify level and distribution of prehospital care providers, minimum and maximum numbers of designated trauma services, complete plans, and begin injury prevention and trauma training programs between July 1990 and 1992. The DOH was required to complete rules development to include standards for verification and designation, trauma registry implementation, and regional quality improvement (QI), and to identify the minimum and maximum numbers of prehospital verified services and hospital designated services by 1992. The Steering Committee and DOH determined that the level I trauma service distribution would be determined 
based on statewide needs and that levels II to $\mathrm{V}$ be based on approved regional plans defining regional needs. In July 1993, the designation process was required to begin. In December 1993, Harborview Medical Center was designated as the only level I trauma service in Washington State. This decision was based on the state population need and the desire to maintain a high-volume academic center focused on advancing the care of injured patients. The central region, which encompasses King County, Washington, and includes Harborview Medical Center, recommended not to designate any competing level IIs in the region and focus on the distribution of level III and IV centers. Figure 3 shows the current distribution of trauma centers in the central region. Designation for levels II through $\mathrm{V}$ was begun on a region-by-region basis, with the Southwest Region the first region to complete designation in January 1994.

In the meantime, the final recommendation of the 1990 Report to the Legislature, funding for Uncompensated Trauma Care, remained an item for legislative consideration. The 1990 law required $\mathrm{DOH}$ to conduct a study of cost and reimbursement of trauma care in Washington State. Arthur Anderson, a financial consulting firm, was hired to conduct this study of costs compared with reimbursement for hospitals, physicians and prehospital care providers. The result of this report, which forecasted unreimbursed costs of about \$28 million in 1993 dollars, went to the legislature in the summer of 1992 for consideration in the 1993 legislative session.

In 1993 the Washington State Health Care Reform Act, which was intended to provide universal healthcare coverage, was passed. This was expected to include all the needs for unreimbursed care of trauma patients. The next 2 years were devoted to working to assure that the rules developed for implementing this law would provide adequately for trauma care and accommodate a systems approach to trauma patient distribution that got 'the right patient to the right place in the right amount of time'. Then in 1995 the legislature repealed much of the Health Care Reform Act, including universal coverage.

The first full round of designation of trauma care services was completed in 1995 and the system was declared 'turn key', meaning that prehospital care services were required to deliver patients who met the triage criteria to the closest appropriate trauma care services within 30 minutes, according the regional patient care procedures. With the loss of universal coverage, trauma services in Washington were unsure how they would provide the care they 'signed up for' and the hospitals in Tacoma refused to participate in the designation process, sending their major trauma patients to Harborview for care until there could be a solution to the funding issue.

In 1996, the legislature provided a limited stop gap funding of $\$ 4.6$ million from the state general fund to assist in covering the costs of medically indigent patients who were severely injured. In 1997, the Trauma Care Fund Act was passed providing dedicated funding from an administrative charge on vehicle purchases and a surcharge on moving violations into the Trauma Trust Account, which had been established in the 1988 legislation. In January 1998, the state began collecting revenue for the Trauma Care Fund, and today it collects approximately \$24 million/biennium. The legislature has provided federal appropriation to match funds allocated through the state Medicaid plans to provide enhanced reimbursement for trauma care for patients in this program. This adds approximately $\$ 15$ million/biennium to the funding for the system. In addition, the $\mathrm{DOH}$ provides participation grants to all verified prehospital services and designated hospital and rehabilitation services, and supports the medical program directors for EMS agencies.

The current system includes 80 designated trauma centers for adults (1 level I, 6 level II, 24 level III, 36 level IV, and 13 level V centers), 9 designated centers for pediatrics (1 level I, 2 level II, and 6 level III), and 15 designated rehabilitation centers (3 level I adult, 2 level I pediatric, and 10 level II adult). ${ }^{8}$ The distribution of the acute care centers is shown in figure 4. The designation criteria are based on the ACS Optimal Resource Guide for Trauma Care, but the verification and designation processes are both managed by the state $\mathrm{DOH}$. Out-of-state reviewers are used for all level I and II verification visits. With the current system coverage, it is estimated that $80 \%$ of the state population are within 1 hour of a level I or II center by air or ground transport. There have been efforts to support an additional level II center in the central portion of the state, but this has been challenged by gaps in neurosurgical coverage. This model of trauma system development is now being used to develop a comprehensive statewide system for management of acute cardiac events and stroke care. In 2010 legislation was passed to create an emergency cardiac and stroke system, and the management of this system falls under the existing EMS and Trauma Steering Committee, which has been expanded to include representatives from the cardiology and neurology community (table 2).

\section{LESSONS LEARNED}

The process of developing the Medic One programs and Washington State trauma system has generated valuable lessons in how to establish a high-quality, inclusive approach to injury care with structured, appropriate regionalization in high-volume centers with comprehensive services. Many states are currently challenged in defining the appropriate distribution of trauma centers to ensure access while not diluting patient volume and experience from major academic centers, or driving excessive, expensive resource utilization. The process used to develop the Washington State system and the role of Harborview Medical Center may serve as an example of how to strike this balance. A summary of the lessons learned through this approach includes the following:

- Trauma system planning should be based on comprehensive data collection including an objective assessment of the burden of injury across the state/region, current hospital and subspecialty resources, current referral patterns, clinical outcomes of existing centers, prehospital transportation resources, and geographic constraints to access to care.

- An inclusive approach to designation of rural centers improves provider education, access to initial care, and a structured approach to triage and transfer.

- A lead agency at the state level needs to be identified and governance of the system should be multidisciplinary and involve all relevant stakeholders in both rural and urban and across the continuum of care.

- A regional structure should be established to allow for flexibility in local planning, local education of providers, ongoing regional quality improvement activities, and implementation of injury prevention activities.

- Decisions regarding number and distribution of trauma centers and prehospital resources should be based on population need, and changes should be justified by defined metrics.

- Level I and II centers should be regional referral centers with a goal to concentrate severe injuries in high-volume 
centers with concentrated expertise and resources. Maintaining limited, high-volume level I centers provides excellent patient outcomes and opportunities to optimize educational and research programs to advance trauma care.

- Integration with the EMS system is vital to ensure consistent triage and standardized prehospital care for injured patients. A mechanism needs to be in place for joint quality improvement activities.

- The continuum of care should be included in system planning such as designation of rehabilitation centers and prehospital trauma agencies and aeromedical resources.

- A statewide trauma registry is critical for ongoing system refinement and QI. Data reporting to the registry must be mandatory for all centers.

- Sustainable system funding is vital to support system participation by all stakeholders and offset the costs of uncompensated and undercompensated care.

- Integration of paramedic training and skill maintenance in major trauma centers provides high-quality EMS training and fosters collaboration for research and advances in patient care.

- Segregation of major surgical programs between hospitals within an academic medical center allows for focused allocation of resources and minimizes competition for OR time and other critical resources.

- Safety net, trauma center resilience, and sustainability are enhanced by a broad-based clinical mission, which includes other surgical emergencies and subspecialty elective care.

- The model of trauma system development and regionalization can be extended to other time-sensitive diseases, such as ruptured abdominal aortic aneurysms, acute coronary events, and stroke care.

Contributors All authors contributed substantially to the manuscript including submission of historical documents, personal interviews to verify historical facts, and drafting and critical review of the manuscript.

Competing interests None declared.

Provenance and peer review Commissioned; externally peer reviewed.

Open Access This is an Open Access article distributed in accordance with the Creative Commons Attribution Non Commercial (CC BY-NC 4.0) license, which permits others to distribute, remix, adapt, build upon this work non-commercially, and license their derivative works on different terms, provided the original work is properly cited and the use is non-commercial. See: http://creativecommons.org/ licenses/by-nc/4.0/

(C) Article author(s) (or their employer(s) unless otherwise stated in the text of the article) 2017. All rights reserved. No commercial use is permitted unless otherwise expressly granted.

\section{REFERENCES}

1 Maier RV. Seattle's Harborview Medical Center, 1877-2003. Arch Surg 2004:139:14-15.

2 History of Medic one, UW Medicine Paramedic training. http://uwpmt.org/node/17 (accessed 26 Apr 2017).

3 Bulger EM, Copass MK, Maier RV, I. et aAn analysis of advanced prehospital airway management. J Emerg Med 2002;23:183-9.

4 Griffith J, Hogan S. Washington's Regional System for Trauma Care. Washington Public Health 1991.

5 Esposito TJ, Nania J, Maier RV. State trauma system evaluation: a unique and comprehensive approach. Ann Emerg Med 1992;21:351-7.

6 Washington state trauma project: A report to the Washington state legislature by the Washington state trauma advisory committee. 1-5, 1990.

7 Ullmann CY. When the care's not there: A special report on the trauma care crisis in Pierce County. Tacoma New Tribune 1996.

8 Washington State Department of Health. Trauma in Washington State: a chart report of the first 15 years, 1995-2009. www.doh.wa.gov/portals/1/Documents/Pubs/689001. pdf (accessed 26 Apr 2017). 